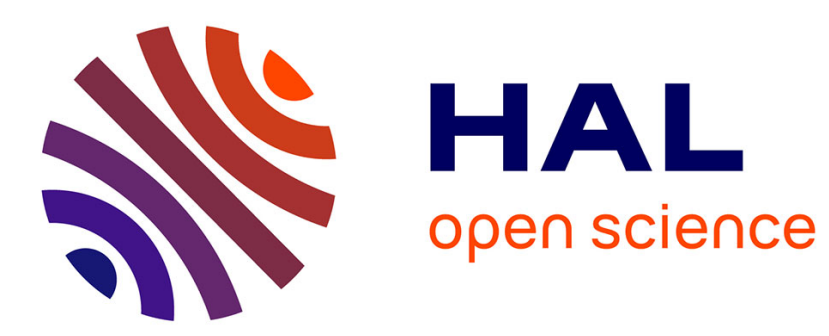

\title{
Project risk management processes: improving coordination using a clustering approach
}

Franck Marle, Ludovic-Alexandre Vidal

\section{To cite this version:}

Franck Marle, Ludovic-Alexandre Vidal. Project risk management processes: improving coordination using a clustering approach. Research in Engineering Design, 2011, 22, pp.189-206. 10.1007/s00163011-0106-9 . hal-01171190

\section{HAL Id: hal-01171190 \\ https://hal.science/hal-01171190}

Submitted on 3 Jul 2015

HAL is a multi-disciplinary open access archive for the deposit and dissemination of scientific research documents, whether they are published or not. The documents may come from teaching and research institutions in France or abroad, or from public or private research centers.
L'archive ouverte pluridisciplinaire HAL, est destinée au dépôt et à la diffusion de documents scientifiques de niveau recherche, publiés ou non, émanant des établissements d'enseignement et de recherche français ou étrangers, des laboratoires publics ou privés. 


\title{
Project risk management processes: improving coordination using a clustering approach
}

\author{
Franck MARLE ${ }^{1}$, Ludovic-Alexandre VIDAL ${ }^{1}$ \\ ${ }^{1}$ : Assistant Professors, Laboratoire Genie Industriel, Ecole Centrale Paris, Grande voie des vignes, 92290 Chatenay- \\ Malabry, France \\ Corresponding author: franck.marle@ecp.fr, (33)141131568 (phone), (33)141131272
}

\begin{abstract}
Projects are dealing with bigger stakes and facing an ever-growing complexity. In the first place, project risks have increased in number and criticality. Lists of identified project risks thus need to be broken down into more manageable clusters. Existing techniques for this are generally based on a well-known parameter such as the nature of the risk or its ownership. The limits of this approach are that project risk interactions are not properly considered. Project interdependent risks are thus often analysed and managed as if they were independent. The consequence is that there may be a lack of consideration of potential propagation through this risk network. A change may have dramatic consequences if the propagation chain is not clearly identified and/or not managed. Our objective in this paper is to propose a methodology for grouping risks so that the project risk interaction rate is maximal inside clusters and minimal outside. What we hope to achieve is a method which facilitates the coordination of complex projects which have many interrelated risks with many different risk owners. We contend that the capacity of risk owners to communicate and make coordinated decisions will be improved if they are grouped in such a way. This proposed reconfiguration of organisation is complementary to existing configurations. To do this, we first model project risk interactions through matrix representations. Then, the mathematical formulation of the problem is presented and two heuristics are introduced. A case study in the civil engineering industry (a large infrastructure public-private partnership project) is presented, which enables us to propose global recommendations, conclusions and perspectives.
\end{abstract}

Keywords: Project risk management Change management Complex Interactions Organisational reconfiguration Clustering 


\section{Introduction}

A project is "a temporary and unique endeavour undertaken to deliver a result". It generally corresponds to the creation of a unique product or service which brings beneficial change or added value. Project systems are in essence complex (Vidal and Marle 2007). This complexity is undoubtedly a major source of risk in projects, since the project organisation may not be able to cope with it. Propagation effects throughout the project structure are likely to notably reduce the performance of the risk management process (Eckert et al. 2004). Particular attention should be paid to this performance since poor or delayed risk mitigation decisions may have great potential consequences in terms of crisis, underachievement of objectives and avoidable waste (Kloss-Grote and Moss 2008).

In this paper, we propose to address project risk management from the perspective of managing complexity through the interaction between risks. In complex projects such as new product development projects or construction projects, risks are becoming ever more numerous and interdependent (Iyer and Mohammed 2010). This is due to both technological and organisational complexity. In order to manage them better, this paper proposes a reconfiguration of risk groups. An optimisation algorithm is introduced in order to maximise the amount of interactions within the groups. This involves a reconfiguration of interfaces between the actors who manage these risks, since they are gathered into new groups. The objective is to constitute smaller risk groups which are still manageable (due to their limited size) but enable propagation effects to be better managed. Indeed, the major part of risk interactions is likely to be within these clusters. The ultimate objective with this approach is to improve coordination during the project risk management process.

The paper is organised as follows. After a consideration of current risk classification approaches (section 2), we explain how risk interactions can be modelled through the use of matrix representations and graph theory (section 3). We then focus on an interaction-based risk clustering methodology, developed to reconfigure an organisation (section 4). Our approach is tested on a large project which is introduced in section 2 and detailed in following sections. This project is the implementation of an entire tramway infrastructure in a city, including the design and delivery of the trains (the rolling stock) and other operating systems (like signalling material or communication systems), and of course the construction of all the infrastructures, including the buildings, tracks and bridges.

\section{Related work and problem setting}

In the following section we describe the classical methodologies which are used to classify risks. After showing their 2 
limits, the problem is set and the research methodology is proposed. To end, the case study is introduced.

\subsection{Existing project risk grouping methodologies}

Project risks are ever more numerous (from tens to hundreds of risks). It is now mandatory to break this list of risks down into subgroups/clusters so as to have more manageable items. Traditionally, project risk management consists of four successive major steps: risk identification, risk analysis, risk response planning and risk monitoring (PMI 2008). During these steps, several ways to cluster risks together are commonly proposed according to their project risk attributes:

- A first approach is to group them according to their nature (e.g. financial risks or technical risks).

- A second approach is to group them according to one of their numerical attributes such as probability, impact or more frequently criticality (low, average, high).

- A third approach is to group them according to their risk owner.

Initially, the aim of risk clustering processes is to facilitate the coordination and management of risks. But with existing approaches, fieldwork proves us this is not always the case in complex projects. For example, project complexity, such as that described in (Baccarini 1996, Edmonds 1999; Laurikkala et al. 2001) involves specific issues in decision-making under complex situations (Phelan 1995; Earl et al. 2001). Indeed, the complexity of a project makes it impossible to have complete information about the project in question (Suh 1999), and thus to simultaneously visualize all the elements and interactions of a given project (Marle 2002). This is underlined when looking at projects through systems thinking (Simon 1981; Le Moigne 1990). In the end, this may lead to failure and dramatic propagation effects because of the interrelated nature of the project elements (Park and Cutkosky 1999). The problem with current methodologies is that project risk interactions are not explicitly incorporated. For instance, figure 1 shows a project where some links exist between risks (dotted lines), although they are not modelled and thus not managed. Risks are indeed interrelated with complex links. 


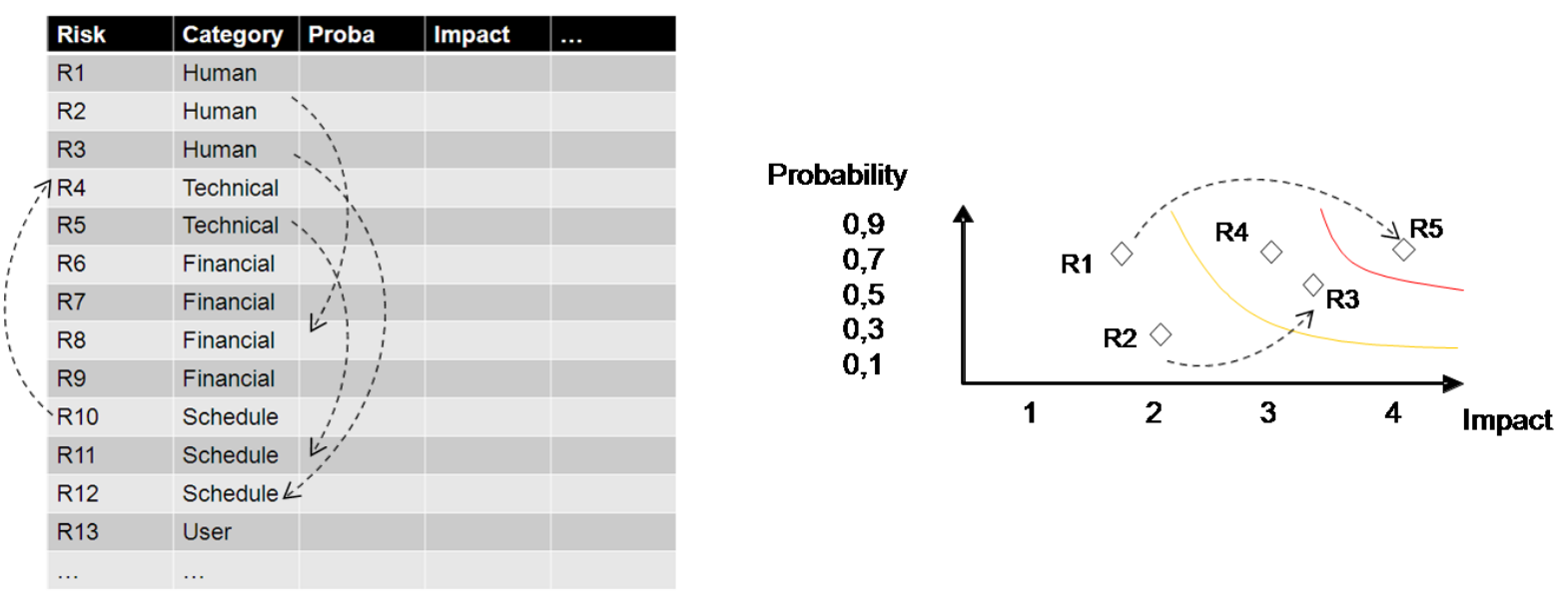

Fig. 1 Classification of project risks by nature and/or by value

Current project management techniques include classical principles underpinning scientific management: the fragmentation of work and the maximisation of visibility and accountability. We argue that projects are nowadays generally managed with single-link trees (WBS, PERT, OBS, risk lists), and not as networks (Marle 2002). In the case of risk management, most of the methods use lists, screening or sorting risks, as seen above. Traditional methodologies are mainly single-risk oriented, analysing their multiple causes and multiple consequences.

However, some studies have been undertaken to model interdependencies between risks. For instance, Bayesian networks (Bouzaïene-Marle 2005) link several risks, from multiple inputs to multiple outputs, but they have specific validity conditions: links must be oriented, and there must not be any loop. This means that in some cases, they fail to reflect the real complexity of the relationships between different project risks. Other complexity-related approaches have been put forward for civil engineering projects. For instance, Durgaprasad and Appa Rao (1997) focused on the estimation of parameter interdependencies through the use of graph theory to develop suitable knowledge-based systems for risk analysis. Another example can be found in Elhag and Wang (2007) where backpropagation neural networks are used to model bridge risk scores in bridge maintenance projects. These studies all make a claim for better integration of risk interdependencies in project risk management processes.

\subsection{Overall problem setting and methodology}

Due to poor coordination, decisions may be blocked, slowed down or ineffective if interactions are inadequately taken into account. There is thus a crucial need for better awareness, consideration and management of project risks, knowing they are intertwined. Actually, whatever the criteria used for the clustering of a given set of project risks, 
and whatever the rigour and detail level used, there will always be interactions between risks which do not belong to the same cluster. However, our aim here is to propose a methodology which will minimize the amount of interactions which are left outside the formed clusters, which is equivalent to maximising the amount of interactions inside clusters.

To answer this problem, we propose the following research methodology. First, we define a process to capture possible risk interactions, which are synthesised using a binary matrix representation. The matrix is then transformed into a numerical one using the Analytic Hierarchy Process pair wise comparison principles (Saaty 1980). From this numerical data, we formulate the quadratic integer programming problem, and this is solved by two iterative constructive algorithms. The results obtained are then compared to classical decompositions, notably in the example of a large infrastructure project (construction of a tramway infrastructure by a French company). After studying the implications of our research on day-to-day management, future research perspectives are outlined. The Tramway case study is presented in the following section to illustrate this.

\subsection{The Tramway project case study}

The industrial background of this study is a large project, which consists in building the infrastructure and associated systems of the future tramway of a city with a population of 750000 . We shall designate the country as $\mathrm{C}$. The lead company is French and is historically a designer/developer of trains, which recently extended its scope by proposing "turn key" projects, including not only the trains, but also the complete infrastructure around the trains.

This project thus comprises:

- The construction of a depot to stock trains and execute their control and maintenance,

- The installation of tracks throughout the city, over land with many steep slopes,

- The delivery of the corresponding trains, including redesign activities if the current version does not fit with city's specific requirements,

- The establishment of a traffic signalling operating system, which gives priority to the tramway so as to guarantee travel time performance levels.

A local industrial partner is undertaking the civil work which is required for the installation of the tramway. This project is a public-private partnership, due to the implication of the local government and its services. The project was put out to tender by the government of country C in 1995, with designation of a number of key players in 1999. 
The project contract was signed in 2002. After negotiations with banks, the government and the future operator (of which the French company is a major share-holder), the final concession contract was signed in 2004. The project was launched in February 2005, and concrete execution in 2006. A project risk management process was implemented and led to the existence of 8 lists of risks which contributed to the successive risk reviews. Our focus here is on one particular product line known as "System" which, as it integrates all the aspects of the project, is one of the most complex. The 42 risks indicated in the list are diverse and are classified according to six risk classes (risk nature): contractual, financial, technical, project management, stakeholder management and country. Risk ownership in terms of responsibility is shared by 12 actors in the project.

\subsection{Application to different types of projects}

This case study is a mix of two types of projects, respectively infrastructure construction and product development (redesign of an existing product). Even if the proposed methodology has not been tested on pure design projects, it is thus applicable to them. Moreover, this approach enables to mix different types of risks in the case of complex projects like the implementation of a tramway system in a city. For instance, section 4 will detail a particular delivery delay risk, which is a mix of infrastructure-related (depot building, tracks) and design-related (train requirements, track installation machine design) aspects which both influence global project performance. Product development projects (whether design or redesign) and construction projects start with a contract including objectives and requirements related to the project and the product (the result of the project). The project is just one phase of the product lifecycle. Other phases are often called "manufacturing", "distribution", "sales", "use", "maintenance" and "recycling or scrapping". For an infrastructure, the phases are quite similar, even if called differently, like "operating", "maintenance" and "decommissioning". Risks that may occur during downstream phases of the product lifecycle are more and more taken into account during the project. One always has to manage simultaneously risks of different natures, interrelated by cause and effect potential relationships, and potentially occurring during or after the project. The main difference (but which may be very significant) is the nature of the initial contract which is:

- for construction projects with an external customer with less uncertainty on objectives and known consequences in case of failure (penalties, damages, trial, profit decrease...),

- for development projects with an internal customer with more uncertainty and unknown (or more difficult to know) consequences of failure (market share, product performance, commercial profit, product reliability, ...), because most of them are detected after the project ends.

6 
The principles which are developed in this paper are about risk clustering, which is quite generic and may be applied to both types of projects.

\section{Capturing risk interactions}

The aim of this section is to build up a matrix which will capture and represent project risk interactions. This matrix is built in two steps. First, a binary matrix representing the existence of potential interaction between each couple of risks is developed. Secondly, each non-null cell is assessed to obtain a numerical matrix. The current organisation of the Tramway case study is then analysed in terms of consistence with the existence and strength of these interactions.

\subsection{Modelling interactions using matrix representations}

The Design Structure Matrix (DSM) represents and visualises relations and dependencies among objects in design engineering. The same objects are both in the rows and columns of the square matrix. The DSM was introduced by Steward (1981) and was initially used for planning issues (Eppinger et al. 1994). Since then, it has been widely used with other objects, like product components, projects or people (Eppinger and Salminen 2001; Sosa 2008). We propose to use the concept of DSM for project risks. The main advantages of this approach are to overcome the problems associated with the visual display of complex networks and to facilitate calculations inherent to the matrix format (eigenvalues, matrix product and matrix transposition). An additional advantage is that it allows for systematic identification by considering each cell across the matrix. In a similar manner to tasks, components, projects and people, project risks are (or can at least be supposed to be):

- in a finite number, since a project is in essence temporary, with finite resources, objectives, means, etc., i.e. a finite number of elements,

- managed during the project management process, with a limited time window,

- interrelated, notably because of project complexity factors (Vidal and Marle 2008).

It is this interrelatedness which justifies the use of such a methodology for complex interactions management. We define risk interaction in terms of the existence of a possible cause and effect relationship between two risks $R_{j}$ and $R_{i}$, which means that if $R_{j}$ occurs, then $R_{i}$ is likely to result. We define the Risk Structure Matrix (RSM) as the square matrix with $\mathrm{RSM}_{i j}=1$ when there is an interaction from $R_{j}$ to $R_{i}$. When the probability of $R_{j}$ triggering $R_{i}$ is zero, then $\operatorname{RSM}_{\mathrm{ij}}=0 . \mathrm{RSM}$ is a binary matrix. This is new to use the DSM approach for modelling risk interactions, but the 
originality of this paper is to break down these risks into smaller and more manageable clusters using this interactions-based approach. The DSM modelling is just a modelling tool which enables this clustering issue to be addressed.

This RSM needs to be transformed into a numerical one to assess the strength of risk interactions. To do this, two approaches are considered. The first one is to evaluate them directly on a 10-level Likert scale using expert judgment. A second possibility is to use pair wise comparisons, such as the ones used in the Analytic Hierarchy Process (Saaty 1980). Similarly to Chen and Lin (2003), Vidal et al. (2009) propose a five step approach to capture the strength of risk interactions, which enables the Risk Numerical Matrix (RNM) to be constructed.

\section{Step 1: Decomposing individual sub-problems}

For each risk $R_{i}$, we isolate the risks which are related with $R_{i}$ in column (possible effects) and in row (possible causes). This permits a sanity check because each relationship has to be expressed two times (from $R_{i}$ to $R_{j}$ and $R_{j}$ to $R_{i}$ ). This identification enables to generate the Binary Cause (or Effect) Vectors, which are relative to one risk $R_{i}$, respectively called $B C V \mid R_{i}$ and $B E V \mid R_{i}$.

\section{Step 2: Evaluating the strength of interactions}

We build up two matrices called Cause or Effect Comparison Matrices and related to one risk $\mathrm{R}_{\mathrm{i}}$ (respectively $C C M \mid R_{i}$ and $\left.E C M \mid R_{i}\right)$. The Analytic Hierarchy Process is based on the use of pair wise comparisons, which lead to the elaboration of a ratio scale. In our case, we have two parallel pair wise comparison processes to run.

The first one consists in the ranking in rows for each project risk. The criterion on which the alternatives are evaluated is the contribution to $\mathrm{R}_{\mathrm{i}}$ in terms of risk input: in other terms, for every pair of risks which are compared, $\mathrm{R}_{\mathrm{j}}$ and $\mathrm{R}_{\mathrm{k}}$ (thus following $\mathrm{RSM}_{\mathrm{ij}}=\mathrm{RSM}_{\mathrm{ik}}=1$ ), the user should assess which one is more important to risk $\mathrm{R}_{\mathrm{i}}$ in terms of probability to be triggering the risk $\mathrm{R}_{\mathrm{i}}$. Numerical values express these assessments thanks to the use of the traditional AHP scales. The second one is the ranking in columns, according to the same principles.

\section{Step 3: Consolidating the results}

Eigenvectors of each matrix $E C M \mid R_{i}$ and $C C M \mid R_{i}$ are now calculated. It enables to find the principal eigenvectors, relative to the maximal eigenvalue. They are called the Numerical Cause or Effect Vectors and are relative to one risk $\mathrm{R}_{\mathrm{i}}\left(\mathrm{NCV}_{\mathrm{i}}\right.$ and $\left.\mathrm{NEV}_{\mathrm{i}}\right)$. Consistency of the results should be tested thanks to the AHP consistency index.

\section{Step 4: Aggregating the results}

For each risk $\mathrm{R}_{\mathrm{i}}$, Numerical Cause or Effect vectors are respectively aggregated into Numerical Cause / Effect 8 
Matrices (NCM and NEM). The i-th row of NEM corresponds to the eigenvector of CCM|R $\mathrm{R}_{\mathrm{i}}$ which is associated to its maximum eigenvalue. The $\mathrm{j}$-th column of NCM corresponds to the eigenvector of ECM $\mid \mathrm{R}_{\mathrm{j}}$ which is associated to its maximum eigenvalue.

\section{Step 5: Compiling the results}

The two previous matrices are aggregated into a single Risk Numerical Matrix (RNM), the values of which assess the relative strength of local interactions. The RNM is defined by a geometrical weighting operation (based on the possible assumption that both estimations can be considered as equivalent). We choose the geometrical mean instead of the arithmetic mean because it tends to favour balanced values (between the two assessments). $\mathrm{RNM}_{\mathrm{ij}}$ is defined as the strength of the cause and effect interaction from $R_{j}$ to $R_{i}$.

The RNM thus permits to synthesize the existence and strength of local precedence relationships between risks as it combines the cause-oriented vision and the consequence-oriented vision of an interaction. Combining these two visions is therefore interesting to avoid any bias or misevaluation which can happen when looking at the problem with only one vision.

\subsection{Case study: analysis of the existing organisation}

Currently, risk management receives moderate attention within the firm and the following issues need to be underlined. In the first place, risk lists are elaborated since they must be done, but no real attention is paid to them and they are not sufficiently exploited. Secondly, risk management is still too often considered as an academic pursuit which is not necessary applicable to day-to-day project management. Thirdly, some risk owners (in terms of responsibility) have been assigned too quickly and without an in-depth analysis of the required skills and experience. Indeed, risk owners belong to varied hierarchical levels in the company structure, and some risk owners are responsible for one risk, while other ones are responsible for more than ten.

When performing the risk interaction identification, new risks appeared, for two reasons. Some were a consequence or cause of other risks already present in the initial list; others were seen as intermediary risks which were useful to explain the link between two or more existing risks. Identification is done on direct cause or effect relationship. But, we ask interviewees whether they think this is a direct link or if new intermediary elements deserve to be included. In the end, the aggregation of local cause-effect relationship identifications enables to display the global risk network. This enables a final meeting to be organised in which interviewees can propose new nodes and connections in the 
risk graph.

One may wonder when to perform this risk interaction identification process and the related analysis of the existing organisation. In most cases, the earlier, the better. Indeed, it enables discussions between people who would not have necessarily been in relation together to be facilitated. However, information may be neither available nor reliable at the very beginning of the project, which may result in constituting irrelevant groups. The decision about the clustering operation schedule (one or several times during the project) should thus be a balance between the necessities to do it early enough and to have enough reliable information. In this case, the project had already been launched before the beginning of the study. Eight risk review meetings had been conducted before our intervention. As a whole, when performing this risk interaction identification process, 14 new risks were identified (see table 1), which represents an increase of nearly $32 \%$ in the number of identified risks. This is a first significant result, as it increases the Identification Efficiency index introduced by Kloss-Grote and Moss (2008). Six of the risks which were present in the initial list $\left(\mathrm{R}_{1}, \mathrm{R}_{8}, \mathrm{R}_{11}, \mathrm{R}_{15}, \mathrm{R}_{23}\right.$ and $\left.\mathrm{R}_{34}\right)$ were considered as poorly interrelated with others and possibly negligible for this study. Finally, this step raises the issue of risk formulation as in Lough et al. (2009), as they were not initially formulated in a standard way, which made it more difficult to identify some interactions. 
Table 1 Global list of risks updated after the risk interaction identification process

\begin{tabular}{|c|c|c|c|}
\hline Risk Id & Risk name & Risk owner & Risk Class \\
\hline 1 & Safety studies & 1 & Technical \\
\hline & Liquidated damages on intermadiate milestone and delay & & \\
\hline 2 & of Progress Payment Threshold & 2 & Contractual \\
\hline 3 & Vehicle storage in another city & 1 & Contractual \\
\hline 4 & Vandalism on site & 3 & Contractual \\
\hline 5 & $\begin{array}{l}\text { Traction/braking function : behaviour in degraded mode } \\
\text { on slope }\end{array}$ & 1 & Technical \\
\hline 6 & New local laws and regulations & 1 & Contractual \\
\hline 7 & Traffic signalling, priority at intersections & 4 & Contractual \\
\hline 8 & $\begin{array}{l}\text { Unclear Interface with the Client, for Infrastructure } \\
\text { equipment }\end{array}$ & 5 & Contractual \\
\hline 9 & Delays due to client late decisions & 5 & Contractual \\
\hline 10 & Travel Time performance & 4 & Technical \\
\hline 11 & Limited Force majeure definition & 2 & Contractual \\
\hline 12 & Operating certificate delay & 2 & Contractual \\
\hline 13 & Reliability \& availability targets & 4 & Technical \\
\hline 14 & Permits \& authorisations & 2 & Contractual \\
\hline 15 & Insurance deductibles & 6 & Financial \\
\hline 16 & Archeological findings & 2 & Contractual \\
\hline 17 & Discrepancies Client / Operator / Concessionaire & 7 & Contractual \\
\hline 18 & Civil Work delay \& continuity & 8 & Contractual \\
\hline 19 & Responsibility of client on Civil Work delay & 2 & Contractual \\
\hline 20 & On board CCTV scope & 9 & Technical \\
\hline 21 & Noise \& vibration attenuation & 4 & Technical \\
\hline 22 & Potential risks of claim from Civil Work subcontractor & 2 & Contractual \\
\hline 23 & Harmonics level & 5 & Technical \\
\hline 24 & Non compliance contractual Rolling Stock & 1 & Technical \\
\hline 25 & Non compliance technical specifications Rolling Stock & 1 & Contractual \\
\hline 26 & Exchange risk on suppliers & 6 & Financial \\
\hline 27 & Track installation machine performance & 10 & Client/Partner/Subcontractor \\
\hline 28 & Tax risk on onshore & 6 & Financial \\
\hline 29 & Additional poles overcost for Tramway Company & 5 & Contractual \\
\hline 30 & Overcost due to Security requirements for trains & 4 & Technical \\
\hline 31 & Track insulation & 9 & Technical \\
\hline 32 & Delay for energising & 5 & $\begin{array}{l}\text { Project management, } \\
\text { Construction site }\end{array}$ \\
\hline 33 & Fare collection requirements & 7 & Contractual \\
\hline 34 & Construction safety interfaces & 3 & Technical \\
\hline 35 & Electromagnetic interferences & 4 & Technical \\
\hline 36 & Exchange risk & 6 & Financial \\
\hline & Risk of partial rejection of our request for EOT & & \\
\hline 37 & (Extension Of Time) & 2 & Contractual \\
\hline 38 & Interface rail / wheel & 4 & Technical \\
\hline 39 & Risk on Certification of our equipement & 11 & Country \\
\hline 40 & OCS installation & 3 & $\begin{array}{l}\text { Project management, } \\
\text { Construction site }\end{array}$ \\
\hline 41 & Banks stop financing the project & 2 & Contractual \\
\hline 42 & Costs of modifications not covered by EOT agreement & 2 & Contractual \\
\hline 43 & Return profit decrease & 2 & Financial \\
\hline 44 & Extra trains & 4 & Contractual \\
\hline 45 & Pedestrian zones & 4 & Technical \\
\hline 46 & Train performance & 1 & Technical \\
\hline 47 & Waiting time at stations & 4 & Contractual \\
\hline
\end{tabular}




$\begin{array}{llll}48 & \text { Depot delay } & 3 & \text { Technical } \\ 49 & \text { Error in the Survey (topography) } & 4 & \text { Technical } \\ 50 & \text { Ticketing design delays } & 7 & \text { Contractual } \\ 51 & \text { Track installation delay } & 3 & \text { Technical } \\ 52 & \text { Reengineering / Redesign } & 4 & \text { Technical } \\ 53 & \text { Slabs pouring delay } & 3 & \text { Technical } \\ 54 & \text { Initial specifications of CW (Civil Work) } & 3 & \text { Technical } \\ 55 & \text { Available cash flow decrease } & 2 & \text { Financial } \\ 56 & \text { Rolling stock delivery delay } & 1 & \text { Technical }\end{array}$

In every risk identification process, there is a limit when considering risks inside or outside the project risk list. Downstream limits are generally the final project results, which may include for instance financial profit and delivery time. In this case, it mainly focused on the final profit, but it also included elements in the post-project phase called operation \& maintenance. Upstream limits are generally decided by experts and project decision-makers, notably depending on the influence or capacity of action that they have on the root causes. The example of $R_{27}$ (track installation machine performance) in the Tramway project is interesting. Even though this risk could have some inputs (mainly technical causes), none is included in the model since the project director does not have any capacity of influencing the performance of this machine, so for him the performance of the machine is just an input.

The assessment of the existing risk interactions was then performed on a 10-level Likert scale. Due to the high expertise of interviewees, no AHP-based evaluation was performed, although we would recommend it in most cases. Some difficulties while performing the assessment were encountered. In particular, this step requires the participation of several experts involved in the project since it necessitates a very wide overview of the project elements and stakes. Furthermore, some bias may be included in the assessment of interactions since it appears that interactions are often conceived in terms of impact and not in terms of precedence. Great attention should thus be paid to that point when analysing the results. 
In the end, a global Risk Numerical Matrix (RNM) for the studied risk network was obtained. Its density is quite low (3\% of non-null values) and no feedback loops are present in it. Figures 2 and 3 show the existing natural communication and coordination paths. In figure 2, groups are shown according to the nature of the risk, since people have roles and skills which are mainly consistent with the class of the risk (contractual, financial, technical, etc). In this matrix, $44 \%$ of interactions take place within groups.

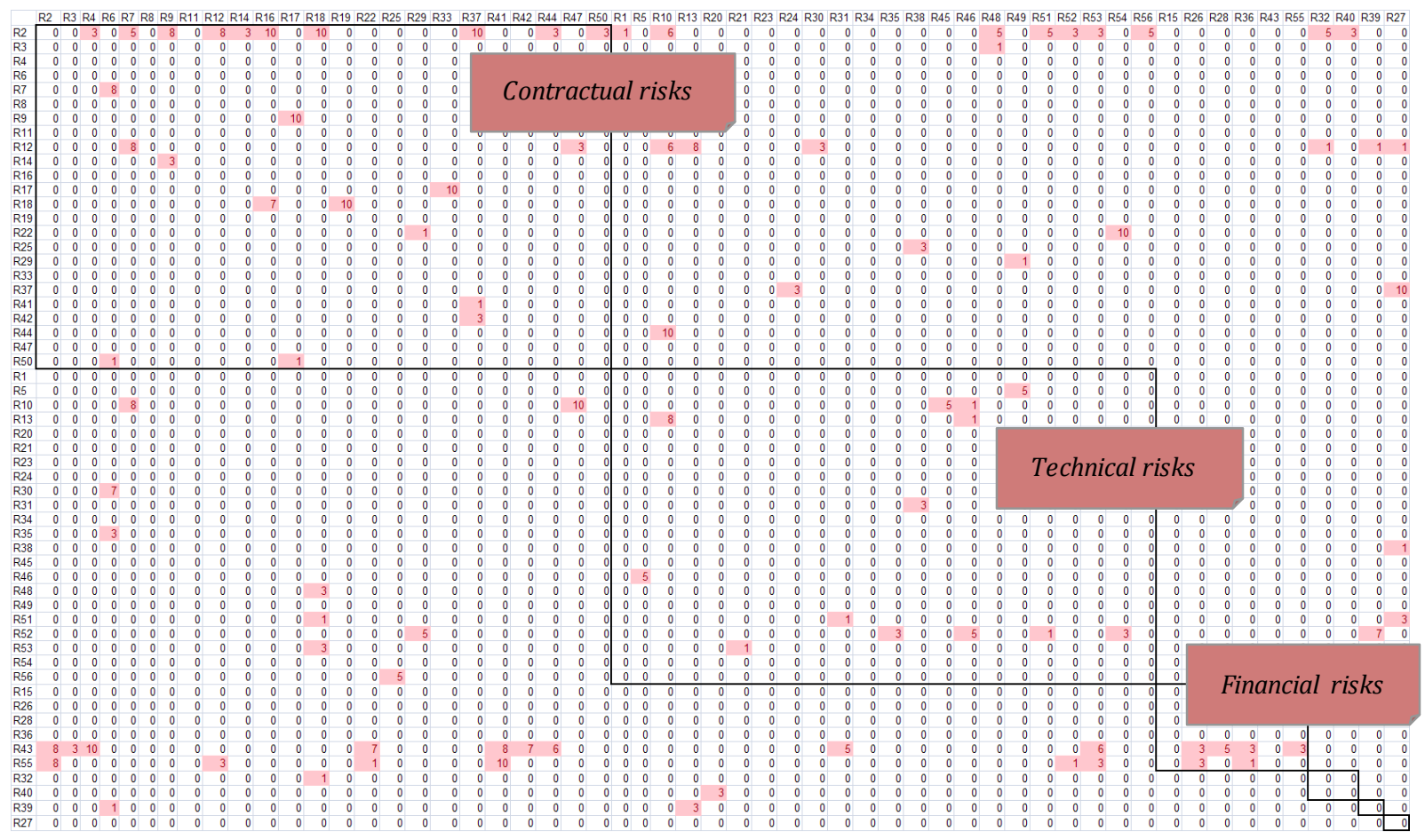

Fig. 2 Existing structure classified by nature of risk (with the names of the three largest groups) 
In figure 3, groups are shown according to risk ownership, since a single person in charge of several risks will - it is to be hoped - more easily coordinate his/her decisions in relation to the whole. In this matrix, $36 \%$ of interactions take place inside the groups. Some of the groups are empty of interactions. That means that people manage several independent risks, while some interactions exist with other persons.

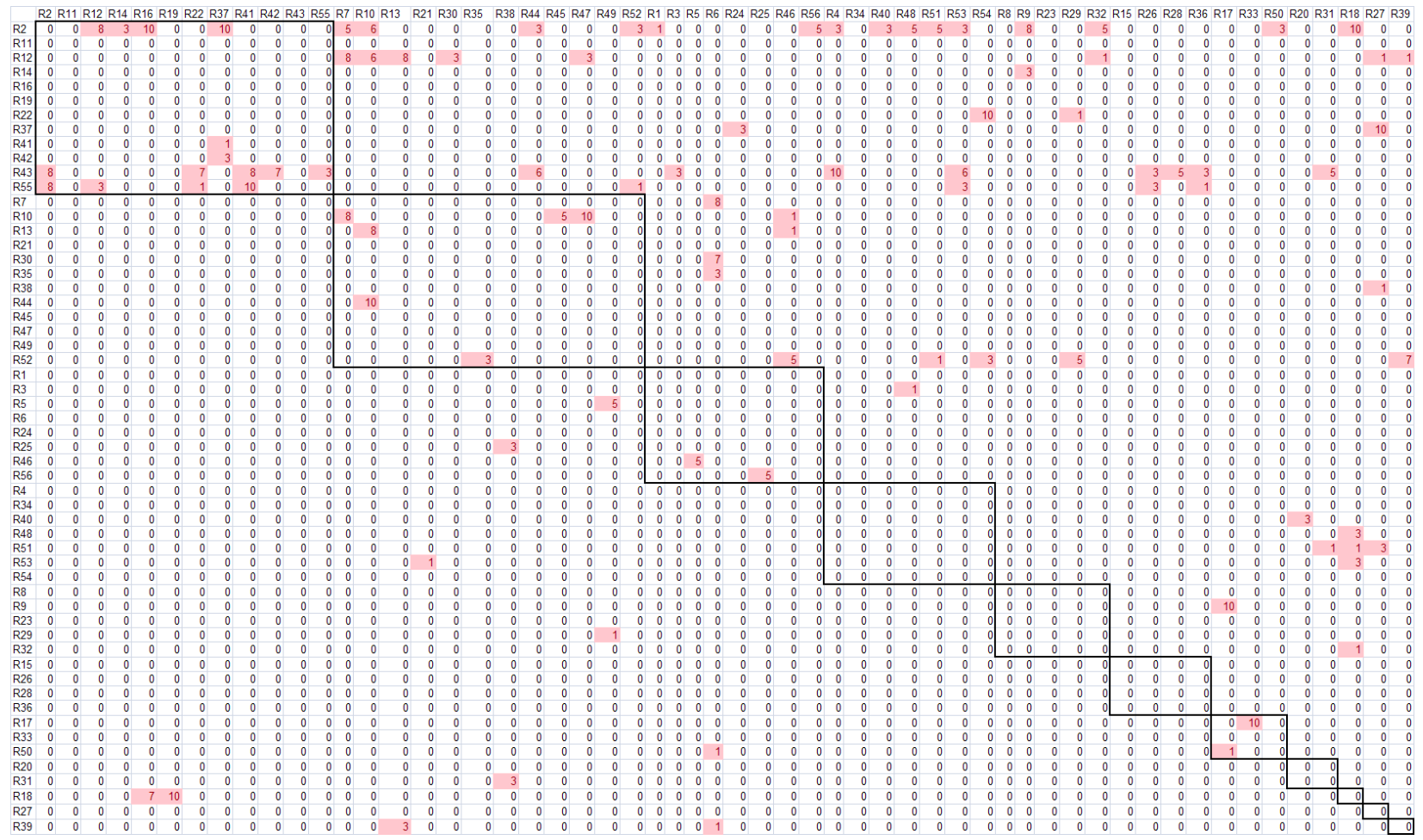

Fig. 3 Existing structure classified by ownership

Due to the number of interactions which are outside these two structures, there is a danger that some propagation may occur without the organisational capacity to cope with it. "Organisational capacity" means the relationship between two or more different risk owners for making decisions about two or more interrelated risks. In the following section, the clustering methodology is introduced. Its aim is to increase the number of interactions within clusters. A desired consequence is an increase in organisational capacity, and a reduction of potential propagation of the occurrence of one or several risks which are specific examples of change in a project. 


\section{Proposed clustering methodology}

In this section, we develop a method to cluster risks in order to maximise intra-cluster interactions given the data of the RNM.

\subsection{Existing clustering methodologies}

The literature on clustering and graph partitioning approaches is extensive. There are two main approaches to clustering operations: vertex similarity-based methodologies and cluster fitness measure-based methodologies.

\subsubsection{Vertex similarity-based criteria and methodologies}

On the one hand, there are several clustering algorithms which are based on similarities between the vertices. These methods are based on the assumption that the higher the vertex similarity, the stronger the need to cluster the vertices together. These measures are mainly based on additional properties of vertices which allow a similarity matrix to be computed. Rather than defining similarity measures, dissimilarity measures such as distance measures are usually defined, for instance the traditional Euclidean and Manhattan distances (Ben-Arieh and Sreenivasan 1999; Hennig and Hausdorf 2006). More advanced distance such as the Jaccard distance (Dong and al. 2006) or the Levenshtein distance (Gusfield 1997) can be used to answer this issue. These measures can be used whether for constructing clusters from singletons, or for breaking the initial graph down into smaller clusters. Some works thus focus on edges that are least central or most "between" clusters, and remove them from the original graph in order to build the strongest clusters with the remaining edges (Girvan and Newman 2002, Freeman 1977).

Some other coefficients can also be calculated to evaluate vertex similarity and perform the corresponding clustering

process. For instance, angle measures such as the cosine similarity (Lakroum and al. 2005) exist. Some important works even try to compare such similarity measures and their impact on clustering operations (Hartigan 1975; Yin and Yasuda 2006). As noticed by Schaeffer (2007), "in some applications, the vertices lack additional properties and there is nothing in the vertices themselves that would allow the computation of a similarity matrix". In this case, vertex similarity measures are often defined by the structural characteristics of the graph. For instance, some measures based on the correlation of the adjacency matrix can be used, such as the Pearson correlation (Rodgers and Nicewander 1988) or the Mahalanobis distance (Mahalanobis 1936). 


\subsubsection{Cluster fitness measure-based criteria and methodologies}

On the other hand, some clustering processes are based on cluster fitness measures, that is to say functions which assess the overall quality and relevance of a given cluster or of a given global clustering solution. The global objective of these methodologies is to identify clustering solutions which directly fulfil a certain property. For instance, methodologies based on graph density measures have been developed in order to partition the initial graph into sub graphs, the density of which should be inferior and/or superior to chosen values (Karp 1977; Kim 2003; Zotteri and al. 2005). But other cluster fitness measures are used as a criterion for graph partitioning. Indeed, as noticed by Schaeffer (2007), "one measure that helps to evaluate the sparsity of connections from the cluster to the rest of the graph is the cut size. The smaller the cut size, the better isolated the cluster". Indeed, cut size-based measures undoubtedly permit to quantify the relative independence of a sub graph to the rest of the graph and have been used in many clustering processes (Shi and Malik 2000; Kannan et al. 2004). Finding the partition which minimises cut-sizes (with restriction conditions on the orders of the sub-graphs) makes it possible to maximise the sum of the weights of the edges which are internal to the clusters. This cut-based measure is of great interest for our case. In order to facilitate complex project risk management, the reduction of interfaces in terms of number, and above all strength, is likely to be desirable. Reducing interfaces is thus very similar to this problem of graph partitioning which aims at minimising the global cut size (since risk interactions are modelled and assessed using edges and their weights).

\subsection{Problem definition}

Let us consider a set of project risks $\left(R_{1} \ldots R_{N}\right)$. Suppose we know the RNM for this set of risks. This INTRA value is defined by the sum of the values of all interactions between risks which belong to a same cluster. The INTER (Inter-cluster global interactions) value is defined by the sum of the values of all interactions between risks which are not paired inside a same cluster. The sum of INTRA and INTER values corresponds to the sum of all risk interactions values, which is constant. As a consequence, maximizing INTRA is equivalent to minimizing INTER.

Let $\mathrm{K}$ be the number of clusters of the optimal clustering solution, which maximises intra-cluster global interactions value. The value of $\mathrm{K}$ is not known in advance. However, some constraints about $\mathrm{K}$ are known. Namely, the goal is to assign project members to clusters in order to better manage the risks which belong to a same cluster, i.e. which are strongly interdependent. It is known that people have a limited capacity to simultaneously manage numerous 16 
objects. We thus follow the hypothesis that in the end, the maximum size of a cluster should be a certain size $S_{\text {max }}$ which is to be defined by the future users. This sets a lower bound of $\mathrm{K}$, which is defined in Equation 1.

$$
K_{\text {min }}=\operatorname{INT}\left(\frac{N-1}{S_{\max }}\right)+1
$$

where INT is the integer part of a real number.

\subsection{Formulating the integer programming problem}

As a whole, the problem which is addressed here is known as the graph K-partitioning problem, the formulation of which is given below. This problem is to be solved for each value of $\mathrm{K}$ which is superior to $\mathrm{K}_{\min }$. We first introduce the following decision variables (Equation 2):

$\forall i, 1 \leq i \leq N, \forall k, 1 \leq k \leq K, x_{i k}=1$

if risk $R_{i}$ belongs to cluster $C_{k}$.

The objective function, which is to be maximised, is as following (Equation 3)

$$
\operatorname{INTRA}=\sum_{k=1}^{K} \sum_{i=1}^{N} \sum_{j=1}^{N} x_{i k} x_{j k} \operatorname{RNM}(i, j)
$$

Problem constraints are the following (Equations 4 and 5).

$$
\forall i, 1 \leq i \leq N, \sum_{k=1}^{K} x_{i k}=1
$$

as we argue for cluster disjunction to enable easier management in practice.

$$
\forall k, 1 \leq k \leq K, \sum_{i=1}^{N} x_{i k} \leq S_{\max }
$$

since we want the maximum size of clusters to be $S_{\max }$ risks, in order to permit the future management of the clusters when cluster owners are designated.

This problem can be made linear (Vidal et al. 2009). In the end, we use OPL (Optimization Programming Language) to solve it. However, its algorithmic complexity is high $\left(\mathrm{O}\left(2^{\mathrm{N}-1}\right)\right)$ and problems over 22 risks appear to be critical when testing. That is why this research is based on some elementary heuristics, which allow us to approximate the optimal solution of the problem. 


\subsection{Using elementary heuristics}

Both of the heuristics proposed here are elementary iterative construction algorithms. They use two different values for clustering conditions, as described in Equations 6 and 7. The first iterative algorithm $\mathrm{IA}_{1}$ is based on the maximum value between two separate clusters. The second one, $\mathrm{IA}_{2}$, is based on the global interactions value between two separate clusters. In both cases, these values are to be maximised at each step.

$$
\begin{aligned}
& \operatorname{Value}_{1}\left(C_{\alpha}, C_{\beta}\right)=\operatorname{maX}_{i \in C_{\alpha}, j \in C_{\beta}} \operatorname{RNM}(i, j) \\
& \operatorname{Value}_{2}\left(C_{\alpha}, C_{\beta}\right)=\sum_{i \in C_{\alpha}, j \in C_{\beta}} \operatorname{RNM}(i, j)+\operatorname{RNM}(j, i)
\end{aligned}
$$

At the initial step, all risks are isolated: every initial cluster is a singleton. The maximum value is obtained for two isolated risks $R_{i 0}$ and $R_{j 0}$, which are grouped into a first cluster $C_{1}$. Then, the maximum value for the second step may be obtained for two isolated risks or for cluster $\mathrm{C}_{1}$ and an isolated risk: in the first case, this forms another cluster $\mathrm{C}_{2}$ and in the second case, $\mathrm{C}_{1}$ is updated with the third element. Step by step, clusters are formed with singletons, by expanding (adding one singleton to an existing cluster), or by merging (two existing clusters). At each step, the previously defined value (Value ${ }_{1}$ or $V$ alue ${ }_{2}$ ) is maximized. When the maximum size of a cluster is reached, the second maximum value is identified and the clustering operation is done on the corresponding interaction if it respects the formulated constraints. This procedure is repeated iteratively until a solution which respects all the constraints is reached.

\subsection{Case study: clustering results}

Even when separating it into its connected components, the problem was too large to be solved by OPL. The use of heuristics was thus necessary. The clustering iterative algorithm was performed to obtain a first good approximate result for the clustering operation. Indeed, algorithm $\mathrm{IA}_{2}$ proved to offer better results in other cases and that is why we chose it in that case (Vidal and Marle 2009).

As a whole, the following clusters were obtained (Table 2). Eckert and co-authors defined (in the context of change propagation in design projects) the four following categories: constants, absorbers, carriers and multipliers (Eckert et al. 2004). Some risks appear to be high accumulation risks (or absorbers), notably the budget-related ones in terms of "profit return" $\left(\mathrm{R}_{43}\right)$, “travel time performance" $\left(\mathrm{R}_{10}\right)$, “rejection of Extension Of Time" ( $\left.\mathrm{R}_{37}\right)$ and "liquidated 
damages" $\left(\mathrm{R}_{2}\right)$. This can be seen on Figure 4 with an important flow of several incoming arrows towards these risks.

These need considerable attention, since many paths in the risk network are likely to lead to them. On the contrary, some risks engender many paths in the risk network, like "Civil Work Delay" $\left(\mathrm{R}_{18}\right)$. They may be the original cause of numerous undesired effects (also called multipliers).

Table 2 Results of the clustering operation

\begin{tabular}{|c|c|c|c|c|}
\hline Risk Id & Risk name & Cluster & Risk owner & Risk Class \\
\hline 2 & $\begin{array}{l}\text { Liquidated damages on intermadiate milestone and } \\
\text { delay of Progress Payment Threshold }\end{array}$ & 1 & 2 & Contractual \\
\hline 10 & Travel Time performance & 1 & 4 & Technical \\
\hline 27 & Track installation machine performance & 1 & 10 & $\begin{array}{l}\text { Client/Partner/ } \\
\text { Subcontractor }\end{array}$ \\
\hline $\begin{array}{l}37 \\
41\end{array}$ & $\begin{array}{l}\text { Risk of partial rejection of our request for EOT } \\
\text { (Extension Of Time) } \\
\text { Banks stop financing the project }\end{array}$ & $\begin{array}{l}1 \\
1\end{array}$ & $\begin{array}{l}2 \\
2\end{array}$ & $\begin{array}{l}\text { Contractual } \\
\text { Contractual }\end{array}$ \\
\hline 42 & $\begin{array}{l}\text { Costs of modifications not covered by EOT } \\
\text { agreement }\end{array}$ & 1 & 2 & Contractual \\
\hline 43 & Return profit decrease & 1 & 2 & Financial \\
\hline 44 & Extra trains & 1 & 4 & Contractual \\
\hline 47 & Waiting time at stations & 1 & 4 & Contractual \\
\hline 55 & Available cash flow decrease & 1 & 2 & Financial \\
\hline 22 & $\begin{array}{l}\text { Potential risks of claim from Civil Work } \\
\text { subcontractor }\end{array}$ & 2 & 2 & Contractual \\
\hline 54 & Initial specifications of CW (Civil Work) & 2 & 3 & Technical \\
\hline 9 & Delays due to client late decisions & 3 & 5 & Contractual \\
\hline 14 & Permits \& authorisations & 3 & 2 & Contractual \\
\hline 17 & Discrepancies Client / Operator / Concessionaire & 3 & 7 & Contractual \\
\hline 33 & Fare collection requirements & 3 & 7 & Contractual \\
\hline 50 & Ticketing design delays & 3 & 7 & Contractual \\
\hline 3 & Vehicle storage in another city & 4 & 1 & Contractual \\
\hline 16 & Archeological findings & 4 & 2 & Contractual \\
\hline 18 & Civil Work delay \& continuity & 4 & 8 & Contractual \\
\hline 19 & Responsibility of client on Civil Work delay & 4 & 2 & Contractual \\
\hline 21 & Noise \& vibration attenuation & 4 & 4 & Technical \\
\hline & Delay for energising & & & $\begin{array}{l}\text { Project } \\
\text { management, }\end{array}$ \\
\hline 32 & & 4 & 5 & Construction site \\
\hline 48 & Depot delay & 4 & 3 & Technical \\
\hline 51 & Track installation delay & 4 & 3 & Technical \\
\hline 53 & Slabs pouring delay & 4 & 3 & Technical \\
\hline 6 & New local laws and regulations & 5 & 1 & Contractual \\
\hline 7 & Traffic signalling, priority at intersections & 5 & 4 & Contractual \\
\hline 12 & Operating certificate delay & 5 & 2 & Contractual \\
\hline 13 & Reliability \& availability targets & 5 & 4 & Technical \\
\hline 29 & Additional poles overcost for Tramway Company & 5 & 5 & Contractual \\
\hline 30 & Overcost due to Security requirements for trains & 5 & 4 & Technical \\
\hline 35 & Electromagnetic interferences & 5 & 4 & Technical \\
\hline 39 & Risk on Certification of our equipement & 5 & 11 & Country \\
\hline 52 & Reengineering / Redesign & 5 & 4 & Technical \\
\hline 5 & $\begin{array}{l}\text { Traction/braking function : behaviour in degraded } \\
\text { mode on slope }\end{array}$ & 6 & 1 & Technical \\
\hline 46 & Train performance & 6 & 1 & Technical \\
\hline 49 & Error in the Survey (topography) & 6 & 4 & Technical \\
\hline 20 & On board CCTV scope & 7 & 9 & Technical \\
\hline 40 & OCS installation & 7 & 3 & Project \\
\hline
\end{tabular}


management,

Construction site

\begin{tabular}{|c|c|c|c|c|}
\hline & Non compliance technical specifications Rolling & & & \\
\hline 25 & Stock & 8 & 1 & Contractual \\
\hline 31 & Track insulation & 8 & 9 & Technical \\
\hline 38 & Interface rail / wheel & 8 & 4 & Technical \\
\hline 56 & Rolling stock delivery delay & 8 & 1 & Technical \\
\hline 1 & Safety studies & & 1 & Technical \\
\hline 4 & Vandalism on site & & 3 & Contractual \\
\hline 8 & $\begin{array}{l}\text { Unclear Interface with the Client, for Infrastructure } \\
\text { equipment }\end{array}$ & & 5 & Contractual \\
\hline 11 & Limited Force majeure definition & & 2 & Contractual \\
\hline 15 & Insurance deductibles & & 6 & Financial \\
\hline 23 & Harmonics level & & 5 & Technical \\
\hline 24 & Non compliance contractual Rolling Stock & & 1 & Technical \\
\hline 26 & Exchange risk on suppliers & & 6 & Financial \\
\hline 28 & Tax risk on onshore & & 6 & Financial \\
\hline 34 & Construction safety interfaces & & 3 & Technical \\
\hline 36 & Exchange risk & & 6 & Financial \\
\hline 45 & Pedestrian zones & & 4 & Technical \\
\hline
\end{tabular}




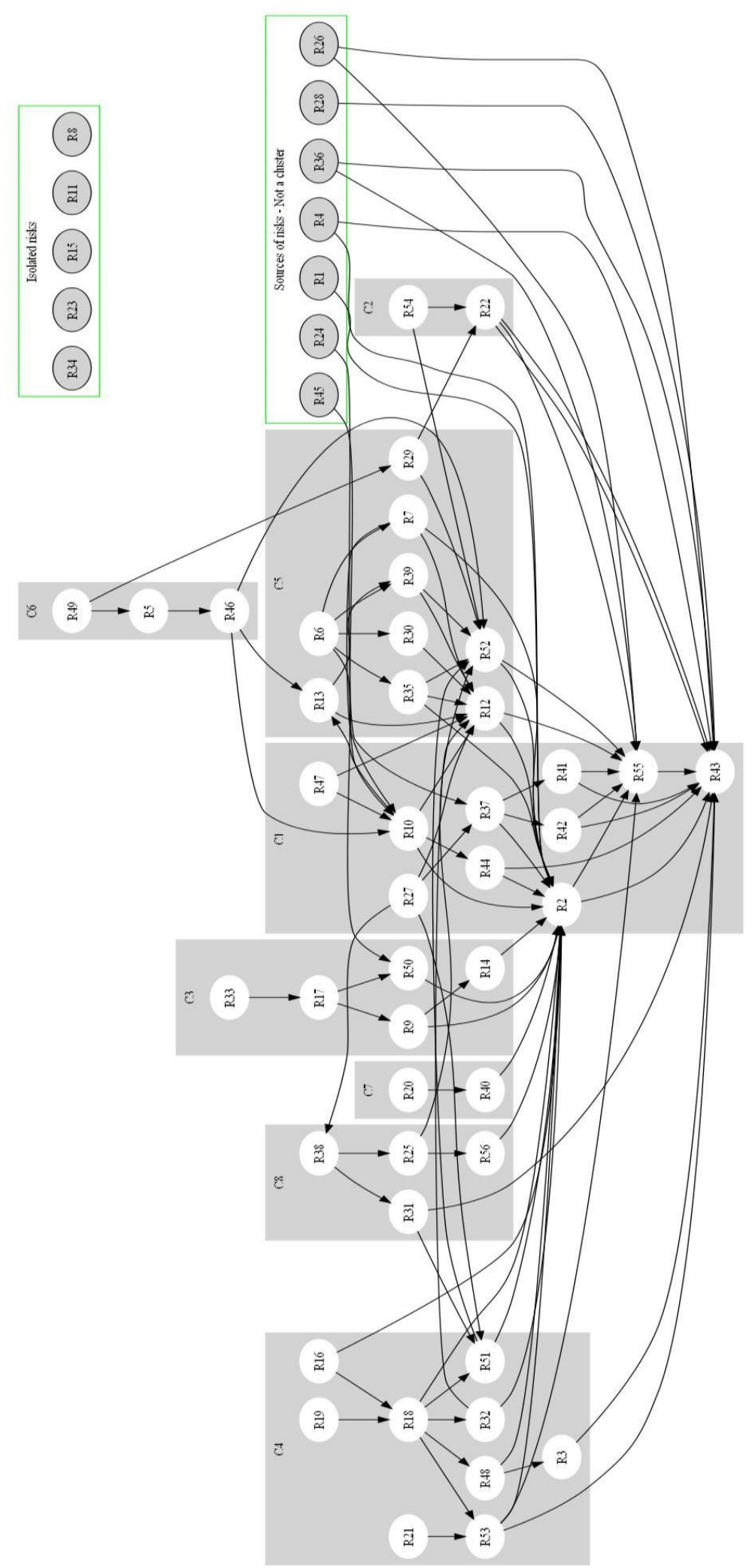

Fig. 4 The clustered project risk network 
The obtained clusters seem to be quite consistent with the fieldwork, as they form groups of risks which seem to be relevant in the task of assisting project risk management. Cluster $\mathrm{C}_{8}$ and $\mathrm{C}_{4}$, for instance, group possible chain reactions which could imply delays (respectively for permits and authorizations, train delivery, depot construction and track installation) and then impact on the final performance indicator which is the profit (in $\mathrm{C}_{1}$ ). The delivery of this part of the project requires simultaneously three things: the depot, the tracks and the trains. If one these are late, then there is a problem with associated damages. The interesting thing is to mix different risks, respectively designrelated risks in cluster $\mathrm{C}_{8}$ and construction-related risks in cluster $\mathrm{C}_{4}$, in order to show their combined influence on a final issue (the depot with the trains on the tracks). The influence of a wrong interface rail / wheel on the redesign of the train and then on the right delivery of the depot including the trains is a link between train design and contractual delivery. The influence of the performance of the track installation machine (which is an internal design) on this contractual intermediary milestone is also noticeable. Finally, a chain starting from a civil work-related risk $\left(\mathrm{R}_{49}\right.$ "error in the topography") and connecting to contractual-related risks $\left(\mathrm{R}_{12}\right.$ "Operating certificate delay" and $\mathrm{R}_{10}$ "Travel time performance") through design-related risks $\left(\mathrm{R}_{5}\right.$ "Traction/braking function" and $\mathrm{R}_{46}$ "Train performance") is another example of heterogeneous propagation chains that is of our interest.

This appears to be all the more interesting since such chain reactions were not previously highlighted and managed during the project. For instance, there were no discussions between actors 1, 2, 3, 4, 5 and 8, respectively owners of risks of cluster $\mathrm{C}_{4}$. In retrospect, this interface should have been particularly highlighted, since three different natures of risks involve the same conclusion, which is a failure in an intermediary delivery milestone. Similarly, actors 1,4 and 9 are encouraged to communicate together about their potential risk interactions. This includes also the link between clusters $\mathrm{C}_{8}$ and $\mathrm{C}_{4}$, for a global understanding of this problem, but with only two clusters with several common actors. With one or two clusters, we are able to group people linked by complex and currently unmanaged potential reaction chains.

Our focus is then what Eckert and co-authors defined as avalanches, the unpredictable propagation of initial events (Eckert et al. 2004). The main difference is that their focus is on product-related change propagation (change requests which are accepted or rejected), even if it enables to build some risk matrices, they are built with product component to component relationships (Clarkson et al. 2004). Our scope is larger because, on the one hand we 22 
include project-related risks, and on the other hand we include all events, including design changes, but not only. They also introduce patterns defining local propagation motifs, relationships between two or three elements (Giffin et al. 2009). We focus on more global patterns, which are potentially combinations of the local ones, like long propagation chains, heterogeneous propagation chains and loops. In these three cases, the anticipation and the coordination in decision-making are very hard, because of the difficulty to connect elements with different natures of risks, different actors, and different occurrence times.

Since we aim at grouping project risks according to their interactions rate, this is inherent to our problem formulation to get heterogeneous clusters. Experience proves us that a project risk cluster typology can quickly be built to describe the obtained clusters. Indeed, there are classically four kinds of clusters (Figure 5) :

- Type A : Risks are clustered together for all/most of them are consequences of a single origin risk $\mathrm{R}_{\mathrm{i}}$.

- Type B : Risks are clustered together for all/most of them are causes of a single accumulation risk $\mathrm{R}_{\mathrm{i}}$.

- Type $\mathrm{C}$ : Risks are clustered together for one of them, a risk $\mathrm{R}_{\mathrm{i}}$, is the cause or consequence of all/most them. They visually correspond to a bow tie situation.

- $\quad$ Type D : Risks are clustered together but without no simple structure, i.e. risks are considerably intertwined.

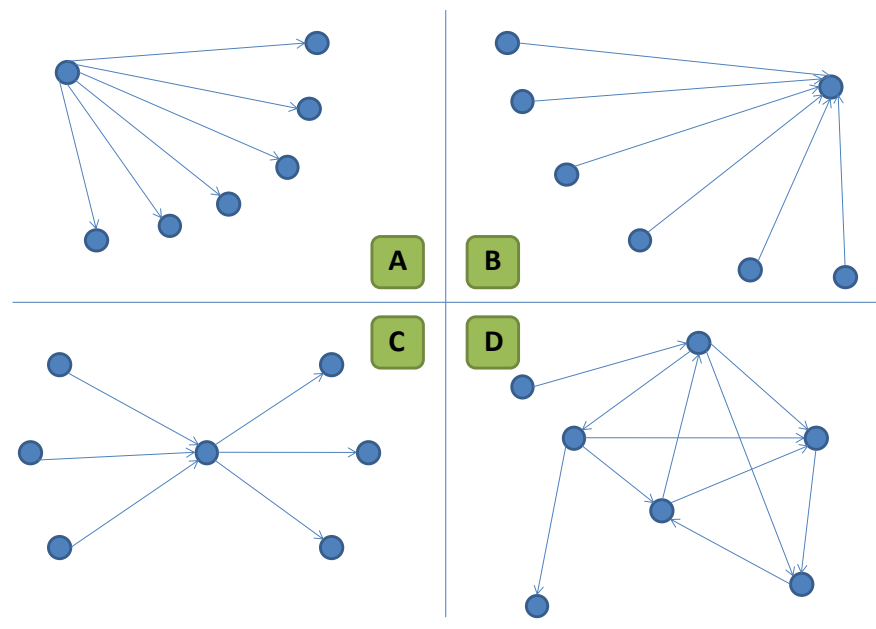

Fig. 5 Clusters typology

An issue which arises is how to assign names to clusters when dealing with such heterogeneous groups. The objective of naming them is to facilitate discussions about each cluster. The difficulty which is mostly encountered 
when naming clusters is to find a denomination which makes sense regarding their constitution. Indeed, interactionsbased risk clusters are generally constituted of many risks of different natures. As a consequence, it is not easy to give meaningful names to them. However, when clusters are of type A, B or C (when going back to the definition of these types), a possibility is to name a cluster by precising its type and naming the corresponding risk $\mathrm{R}_{\mathrm{i}}$. For instance, cluster $\mathrm{C}_{1}$ could be named "Cluster of accumulation to risk $\mathrm{R}_{55}-$ Available cash flow decrease", which underlines the necessity to drive meetings related to $\mathrm{C}_{1}$ regarding this final accumulation point. This enables to understand for instance more easily how a problem about the "waiting time at stations" $\left(\mathrm{R}_{47}\right)$ can finally degrade the project profit.

Another interesting point is to compare the different clustering approaches. In this case, risks were clustered according to the strength of their interactions (Figure 6a), according to their initial risk owner (Figure 6b) and according to their class or nature (Figure 6c). In each figure, clusters are sorted by decreasing value. It is noticeable that in classical configurations, some clusters are relatively or totally empty, which implies for the overall management of some clusters that many unrelated risks have to be coped with, thus decreasing the ability to control possible propagation effects. Moreover, some highly related risks are not in the same cluster, which involves another potential coordination issue. 


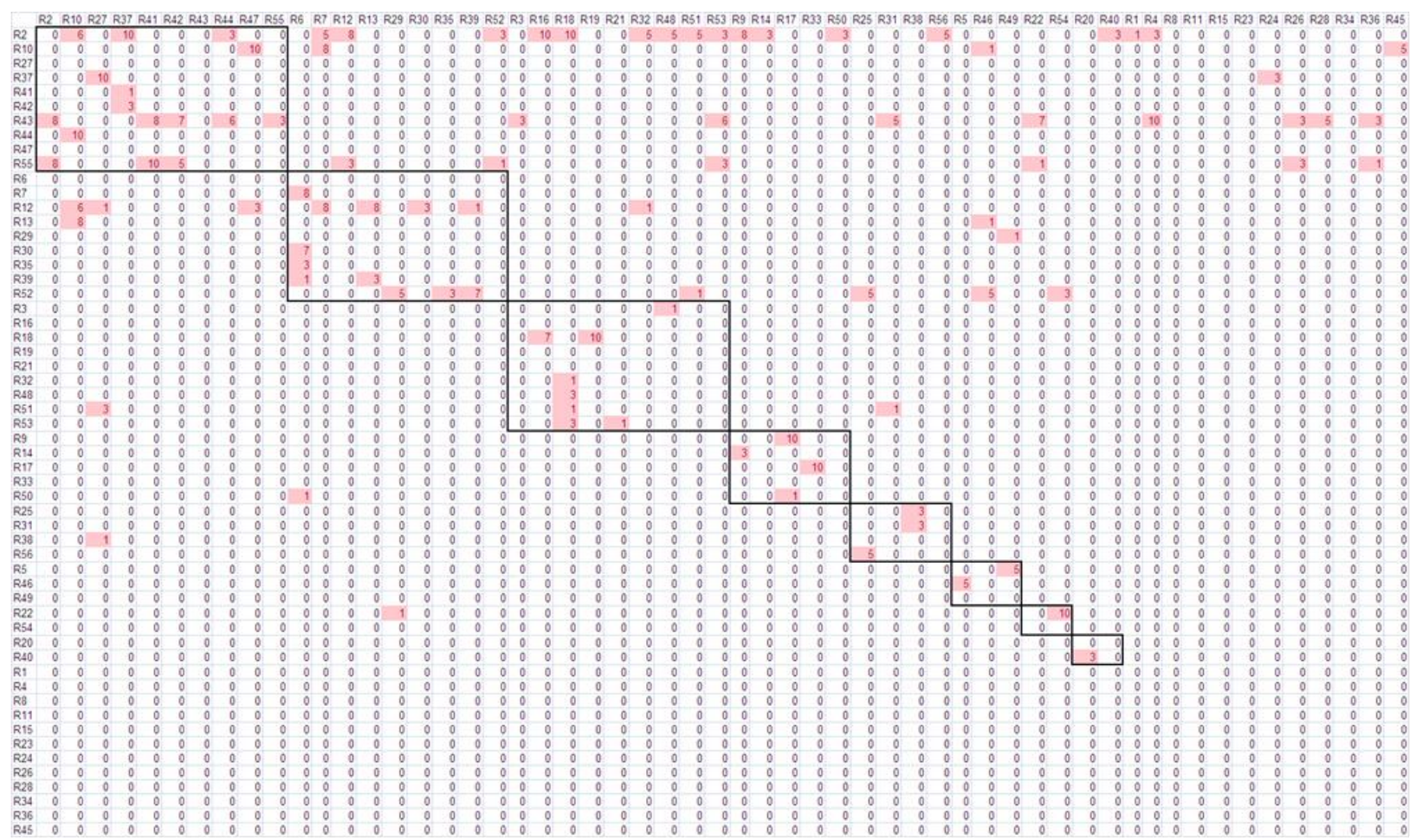

(a)

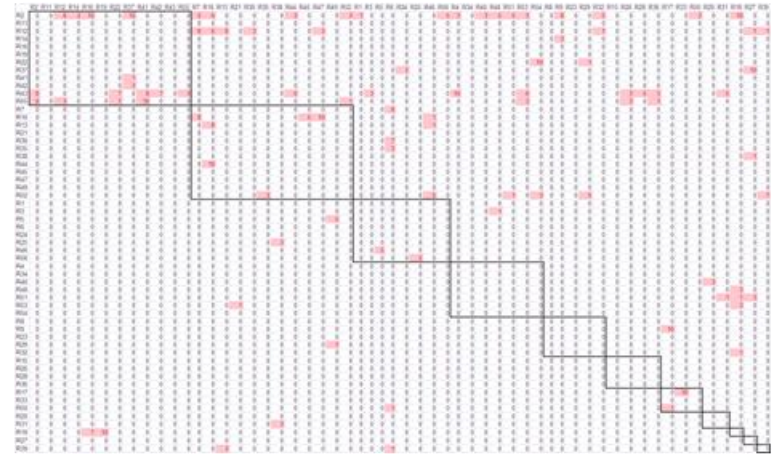

(b)

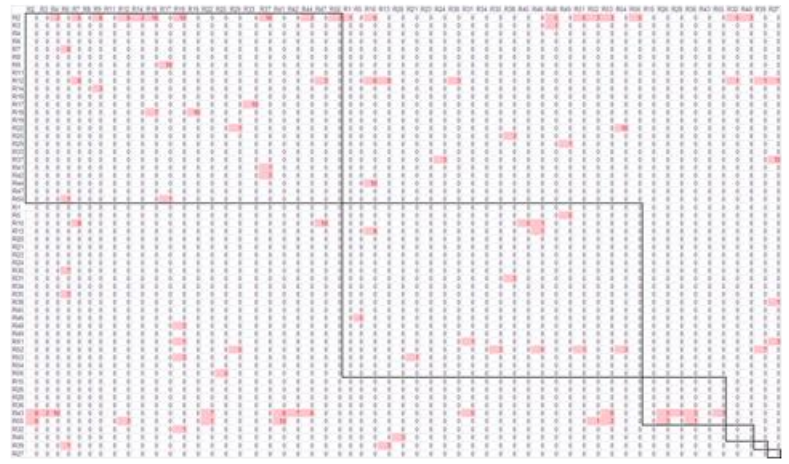

(c)

Figs. 6a, b, c Comparison of clustering by interactions CBI (a), by risk owner CBO (b) and by class CBC (c) When comparing these different alternatives, it can be said that clustering by interactions leads to an important improvement regarding the consideration of interactions (as shown in figure 7). Indeed, the intra-cluster value of CBI is increased by $32 \%$ when comparing with $\mathrm{CBC}$ and by $61 \%$ when comparing with CBO. Moreover, this increase is all the more noticeable given that some risks are left outside clusters in the case of CBI, meaning that the formed clusters are denser. In terms of value, $\mathrm{CBI}$ is as balanced as CBO (standard deviation of clusters value) but with a double mean value. At the same time, $\mathrm{CBI}$ is close to $\mathrm{CBC}$ in terms of mean value, but with a standard deviation 
which is much lower. In terms of cluster size, $\mathrm{CBI}$ has far smaller clusters than $\mathrm{CBC}$ with a more balanced structure.

\begin{tabular}{|c|c|c|c|c|c|c|c|}
\hline & $\begin{array}{c}\text { Total Intra-cluster } \\
\text { value }\end{array}$ & $\begin{array}{c}\% \text { Intra-cluster } \\
\text { value }\end{array}$ & $\begin{array}{c}\text { Mean cluster } \\
\text { value }\end{array}$ & $\begin{array}{c}\text { Std dev cluster } \\
\text { value }\end{array}$ & $\begin{array}{c}\text { Mean cluster } \\
\text { size }\end{array}$ & $\begin{array}{c}\text { Stdev cluster } \\
\text { size }\end{array}$ & $\begin{array}{c}\mathrm{Nb} \text { of risks inside } \\
\text { clusters }\end{array}$ \\
\hline Clustering by interactions (CBI) & 250 & $56 \%$ & 31 & 33 & 5,50 & 3,12 & 44 \\
\hline Clustering by risk owner (CBO) & 155 & $36 \%$ & 14 & 27 & 5,09 & 3,96 & 56 \\
\hline Clustering by class (CBC) & 189 & $44 \%$ & 38 & 48 & 9,17 & 9,89 & 56 \\
\hline
\end{tabular}

Fig. 7 Comparison of clustering approaches

\subsection{Case study: managerial implications}

In the end, our clustering approach permits to suggest an organisational structure which is complementary to the existing one(s). The interest of having different structures is to organise meetings with different groups of actors who will exchange on specific aspects of the project (tasks, risks). It is up to the manager to define the number and frequency of group meetings, depending on the complementarities and relevance of each structure.

The reconfiguration of an organisation raises the issue of risk ownership and risk cluster ownership. Indeed, it appears that within clusters, there are numerous different risk owners and often numerous different classes. Interfaces between actors are then highlighted and need to be managed. The point is to improve coordination between all the risk owners within a same cluster. This reconfiguration may make risk owners more aware of the possible implications of the decisions they make.

A first managerial suggestion comes from the industrial practitioners who participated in the study. They proposed that, for each cluster, all the risk owners who are present in it should initiate discussions during a first meeting and then nominate/vote for a Risk Cluster Owner (RCO). The RCO is accountable for facilitating coordination between the interrelated risks and for anticipating the potential behaviour of this part of the risk network. One of the possible nominees for this responsibility could be the lowest common manager (LCM) in the hierarchical structure of the project, since RCOs need to have a transversal vision of the project and a sufficient level of authority. The notion of LCM was inspired by the mathematical notion of lowest common multiple. The lowest common multiple of two integers $a$ and $b$ is the smallest positive integer that is a multiple of both $a$ and $b$. In our case, the Lowest Common Manager of actors $A_{1}$ and $A_{2}$ is the first common manager of both actors when analyzing upwards the hierarchical structure of the project.

Moreover, in order to obtain helpful results using this methodology, other suggestions were proposed. It seems necessary to:

- Perform pertinent risk identification, risk interactions identification and risk interactions assessment 
processes to obtain a reliable and complete description of the situation. It is also preferable to have the same hierarchical level in the risk structure in order to study same level risks in the chain reactions.

- Carefully identify, during the initial step, risk owners, i.e. the actors who seem to be the most appropriate ones to hold the responsibility for each risk.

- Communicate about the clustering approach so that project members understand its potential benefits.

Finally, particular attention should be paid to some specific phenomena which are related to the complex structure of the risk network:

- possible long chain reactions, especially when the propagation chain is composed of heterogeneous risks (in terms of class, value or risk ownership);

- loops, since they introduce the possibility of amplification of an initial event;

- accumulation risks, since they are likely to be the final expression of numerous propagation chains;

- $\quad$ origin or source risks, since they are likely to trigger many propagation chains.

\section{Conclusion}

This paper presents an innovative risk clustering approach for efficient project risk management. The methodology enables comparisons between several possibilities for grouping risks in a project using several indicators: the total value of interactions inside the clusters and the structure of the clustering solution, in terms of cluster size and cluster value. Our aim is not to criticise the use of classical approaches. On the contrary, the use of complementary classifications which all give powerful insights on the reality of complex phenomena in projects remains perfectly justified.

Since our clustering approach encourages people to meet together and communicate/ coordinate better, we consider that the overall communication / coordination performance is proportional to the performance of our algorithm. Indeed, the amount of interactions within the clusters (which is maximal) is a factual parameter. It determines a maximum potential for communication and coordination within clusters and a minimum risk of non-communication and/or lack of coordination at the interfaces between clusters. However, this potential should be confirmed during the meetings and the day-to-day management of the project. If people are unable to agree and to coordinate, this will remain an untapped potential. It therefore refers to other aspects, such as the possible assignment of relevant Risk Cluster Owners, the use of meeting conducting techniques, collaborative decision-making techniques, general team 
management, etc. In the end, it is difficult to propose an objective measure of this capacity, notably because it is a potential capacity. However, what is particularly important is that the risk of non communication at interfaces is effectively reduced, since its probability decreases. There are less possible non communication situations and the ones that are remaining are the less important ones (regarding their occurrence probability).

The case study brought out the benefits of such an approach, namely greater coordination during the risk management process. It also underlines the need for cooperation and transversal communication within the project team. Fieldwork proves us that it does indeed improve communication between people, since this approach does not seek the identification of responsibility and/or accountability, but the identification of propagation chains and human interfaces. After the clustering process, coordination is facilitated by the Risk Cluster Owner (RCO).

However, this implies that a shift should be operated in the skills of the RCOs. Such project members should indeed show great adaptability since they need to manage heterogeneity inside the cluster(s) they are in charge of. They must have not only technical or project-related skills, but also the capability to manage inter-personal situations with members who have different backgrounds and different goals (Zika-Viktorsson 2005).

The case study which is presented in the paper corresponds to a large project, which mainly includes aspects of civil work and design engineering. We think that the application field has an influence on the nature and number of interactions between risks. When testing the approach on several cases, we saw some differences between construction projects, new product development projects and musical show production projects. Even if the structure of project risk lists may vary (size of the list and density of the interactions between the risks), the clustering method does not depend on the application field and general conclusions about it can be extended to any domain.

Finally, we identify several research perspectives to consolidate this approach:

- Challenging the definition of risk interaction and trying to integrate multiple characteristics (other than precedence relationship) into it.

- Evaluating with greater reliability the strength of interactions between risks. The sensitivity of this evaluation should be explored.

- $\quad$ Exploring more sophisticated graph partitioning heuristics and multi-objective clustering approaches.

- Exploring new constraints to perform other clustering operations, like for instance a maximum number of different risk owners in each cluster, a minimal cluster density or a balanced cluster size. 
- Other clustering approaches exist when managing projects. For instance, the WBS (Work Breakdown Structure) is a major document in project management, consisting of clustering tasks (or deliverables related to tasks) together. The formed clusters can be built taking into account interactions between tasks or not, depending on the maturity of the project organisation. Generally, it is not done according to task interactions, but more according to other parameters, like product components, product functions, departments, resource geographical location, competences and skills, project phases... One of the potential extensions of our risk clustering methodology is therefore to extend it to other project objects (tasks or product components for instance).

- One of remaining questions is the impact of inputs reliability (numerical weights and optimisation problem configuration) on the outputs (the affiliation of risks to clusters). For the moment, we have not run a sensitivity analysis based on uncertainty on weights, which constitutes a research perspective. However, we propose an indirect way to assess the stability of the results by performing a frequency analysis. The objective is to measure the number of times when each couple of risks $\left(R_{i}, R_{j}\right)$ is put together in the same cluster depending on variations on some inputs. The variations have been analysed on problem constraints definition (for instance, the maximum size of clusters) and not yet about the interaction weights, but this issue makes the point of ongoing publications and developments.

- $\quad$ Performing new case studies to validate this approach, especially in other kinds of projects.

\section{REFERENCES}

Baccarini, D. (1996). "The concept of project complexity - a review." International Journal of Project Management 14(4): 201-204

Ben-Arieh, D. and Sreenivasan, R. (1999) Information analysis in a distributed dynamic group technology method.

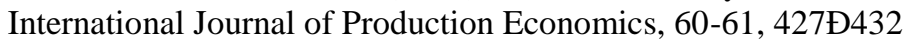

Bouzaïene-Marle, L. (2005). AVISE, Anticipation du Vieillissement par Interrogation et Stimulation d'Experts. Laboratoire Genie Industriel, Ecole Centrale Paris, PhD.

Chen, S. and L. Lin (2003). "Decomposition of interdependent task group for concurrent engineering." Computers and industrial engineering

Clarkson, J., Simons, C. and Eckert, C. (2004) Predicting change propagation in complex design. Journal of Mechanical Design. Vol. 126. Doi: 10.1115/1.1765117

Dong, Y., Zhuang, Y., Chen, K. and Tai, X. (2006) A hierarchical clustering algorithm based on fuzzy graph connectedness Fuzzy Sets and Systems 157, pp. 1760-1774.

Durgaprasad, J. and T. Rao (1997). "Parameter interdependencies for development of KBS for risk analysis." Journal of Computing in Civil Engineering 11(4): 224-230

Earl C., Johnson J. and Eckert C.M.,(2001) Complexity in planning design processes. $13^{\text {th }}$ International Conference on Engineering Design. Glasgow, Scotland

Eckert, C., J. Clarkson and W. Zanker (2004). "Change and customisation in complex engineering domains" 
Research in Engineering Design 15:1-21. DOI 10.1007/s00163-003-0031-7

Edmonds, B. (1999). Syntactic measures of complexity. Faculty of arts. Manchester, University of Manchester. PhD.

Elhag, T. M. S. and Y. M. Wang (2007). "Risk assessment for bridge maintenance projects: Neural networks versus regression techniques." Journal of Computing in Civil Engineering 21: 402-409

Eppinger, S. and V. Salminen (2001). Patterns of product development interactions. International Conference on Engineering Design, Glasgow, Scotland.

Eppinger, S., D. E. Whitney, Smith R. and Gebala D. (1994). "A model-based method for organizing tasks in product development." Research in Engineering Design(6): 1-13

Freeman, L. (1977) "Set of measures of centrality based on betweenness". Sociometry 40:35-41.

Giffin, M., De Weck, O., Bounova, G., Keller, R., Eckert, C. and Clarkson, J. (2009) Change propagation analysis in complex technical systems. Journal of Mechanical Design, Vol. 131 / 081001-1. Doi: 10.1115/1.3149847.

Girvan M. and Newman M. (2002) "Community structure in social and biological networks". Proceedings of the

National Academy of Sciences (PNAS). doi: 10.1073/pnas.122653799, June 11, 2002 vol. 99 no. $127821-7826$

Gusfield, D. (1997) Algorithms on strings, trees and sequences Cambridge University Press.

Hartigan, J.A., (1975) Clustering Algorithms. Wiley

Hennig, C. and Hausdorf, B. (2006) A robust distance coefficient between distribution areas incorporating geographic distances. Systematic Biology, 55(1): 170-175

Iyer, K. C. and S. Mohammed (2010). "Hierarchical Structuring of PPP Risks Using Interpretative Structural Modeling." Journal of Construction Engineering and Management 136(2): 151-159

Kannan, R., Vempala, S. and Vetta A. (2001) On clusterings: good, bad and spectral Working Paper.

Karp, R.M. (1976) Probabilistic analysis of partitioning algorithms for the travelling salesman problem in the plane. Mathematics of Operations Research, vol.2, (no.3), p.209-24.

Kim, S. (2003) Graph theoretic sequence clustering algorithms and their applications to genome comparison in Wu, C.H., Wang, P. and Wang, J.T.L. (Eds.): Chapter 4 in Computational Biology and Genome Informatics, World Scientific, Singapore

Kloss-Grote, B. and M. Moss (2008). "How to measure the effectiveness of risk management in engineering design projects ? Presentation of RMPASS: a new method for assessing risk management performance and the impact of knowledge management - including a few results". Research in Engineering Design 19:71-100. DOI 10.1007/s00163-008-0049-y

Lakroum, S., Devlaminck, V., Terrier, P., Biela-Enberg, P. and Postaire, J.G. (2005) Clustering of the Poincare vectors Image Processing, 2005. ICIP 2005. IEEE International Conference Volume 2, Issue , 11-14

Laurikkala H., Puustinen E., Pajarre E. and Tanskanen K., (2001) Reducing complexity of modelling in large delivery projects. International Conference on Engineering Design. Glasgow, Scotland

Le Moigne, J. (1990). La théorie du système général. Théorie de la modélisation, Presses Universitaires de France

Lough K., M. Van Wie, R. Stone and I. Tumer (2009) "Promoting risk communication in early design through linguistics analyses" Research in Engineering Design 20:29-40

Mahalanobis, P C (1936). On the generalised distance in statistics. Proceedings of the National Institute of Sciences of India 2 (1): 49-55.

Marle, F. (2002). Methods for helping decision-making in projects. PMI Europe Conference, Cannes, France, June 2002.

Phelan, S. (1995). From chaos to complexity in strategic planning. 55th meeting of Academy of Management, Vancouver

PMI, S. C. (2008). A guide to the project management body of knowledge (PMBOK) (2008 ed.). Newton Square, PA, USA., Project Management Institute

Rodgers, J. L. and Nicewander, W.A. (1988) Thirteen Ways toLook at the Correlation Coefficient The American Statistician, 42, 59-66.

Saaty, T. (1980). The Analytic Hierarchy Process: Planning, Priority Setting, Resource Allocation, McGraw-Hill

Schaeffer, S.E. (2007) Graph clustering Computer Science Review I, 27-64

Shi, J. and Malik, J. (2000) Normalized Cuts and Image Segmentation. IEEE Transactions on Pattern Analysis and Machine Intelligence, v.22 n.8, p.888-905

Simon, H. (1981). The Sciences of the artificial. Cambridge The MIT Press

Sosa, M. (2008). "A structured approach to predicting and managing technical interactions in software development." Research in Engineering Design 
Steward, D. (1981). "The Design Structure Matrix: a method for managing the design of complex systems." IEEE Transactions in Engineering Management 28(3): 71-74

Suh, N. (1999) A theory of complexity, periodicity and the design axioms. Research in Engineering Design 11:116133

Tiendung, L., H. C. Carlos, et al. (2009). "Assessing Scope and Managing Risk in the Highway Project Development Process." Journal of Construction Engineering and Management 135(9): 900-910

Vidal, L. and F. Marle (2007). "Modeling project complexity". International Conference on Engineering Design, Paris, FRANCE

Vidal, L. and F. Marle (2008). "Understanding project complexity: implications on project management." Kybernetes, the International Journal of Systems, Cybernetics and Management Science.

Vidal, L., F. Marle and JC. Bocquet (2009). Interactions-based clustering to assist project risk management. International Conference on Engineering Design ICED'09, Stanford, USA

Yin, Y. and Yasuda, K. (2006) Similarity coefficient methods applied to the cell formation problem: A taxonomy and review. International Journal of Production Economics 101, 329-352

Zika-Viktorsson A. and Ritzen S. (2005) Project competence in product development. Research in engineering design 15:193-200 DOI 10.1007/s00163-004-0051-y

Zotteri, G., Kalchschmidt, M. and Caniato, F. (2005) The impact of aggregation level on forecasting performance International Journal of Production Economics 93-94, 479-491 